\title{
The tumor suppressor phosphatase and tensin homolog protein (PTEN) is negatively regulated by NF- $\kappa \beta$ p50 homodimers and involves histone 3 methylation/deacetylation in UROtsa cells chronically exposed to monomethylarsonous acid.
}

\author{
Oliva González C ${ }^{1}$., Jasso-Robles FI $^{1}$., Galicia Cruz OG ${ }^{2}$., Uresti-Rivera EE ${ }^{1}$.; Gandolfi A.J ${ }^{3}$, Escudero-Lourdes $\mathrm{C}^{1}$. \\ ${ }^{1}$ Laboratorio de Inmunotoxicología, Facultad de Ciencias Químicas, Universidad Autónoma de San Luis Potosí. \\ México. \\ ${ }^{2}$ Laboratorio de Fisiología, Facultad de Medicina, Universidad Autónoma de San Luis Potosí. México. \\ ${ }^{3}$ Department of Pharmacology and Toxicology, University of Arizona. Tucson AZ, USA.
}

\begin{abstract}
UROtsa cells have been accepted as a model to study carcinogenicity mechanisms of arsenic-associated human

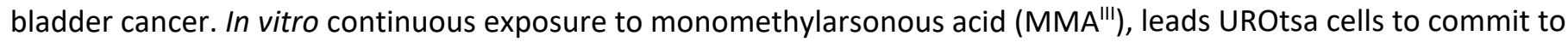
malignant transformation. In this process, NF-k $\beta$-associated inflammatory response seems to play an important role since this transcription factor activates some minutes after cells are exposed in vitro to MMA III and keeps activated during the cellular malignant transformation. It is known that a slight decrease in the protein phosphatase and tensin homologue (PTEN) gene expression is enough for some cells to become malignantly transformed. Interestingly, this tumor suppressor has been proven to be negatively regulated by NF- $\beta$ through binding to its gene promoter. Based on these observations we propose that NF-к $\beta$ may be involved in arsenic associated carcinogenesis through the negative regulation of PTEN gene expression. Changes in PTEN expression and the binding of $\mathrm{p} 50 \mathrm{NF}-\mathrm{k} \beta$ subunit to PTEN promoter were evaluated in UROtsa cells exposed for 4, 12, 20, or 24 wk to 50 nM MMA'". Results showed that MMA ${ }^{\prime \prime \prime}$ induced a significant decrease in PTEN expression around 20 wk exposure to MMA ${ }^{\prime \prime \prime}$, which correlated with increased binding of p50 subunit to the PTEN promoter. Consistent with these results, ChIP assays also showed a significant decrease in $\mathrm{H} 3$ acetylation (H3ac) but an increase in the repression marks H3k9me3 and H327me3 in PTEN promoter when compared with not treated cells. These results suggest that that the activation of NF-K $\beta$ by MMA ${ }^{\prime \prime \prime}$ may participate in UROtsa cells malignant transformation through the negative regulation of PTEN expression involving p50 homodimers-mediated chromatin remodeling around the PTEN promoter.
\end{abstract}




\section{Introduction .}

Epidemiological evidence associates bladder cancer development with chronic human exposure to inorganic arsenic (iAs) (Chiou et al., 2001), however the associated mechanisms are still under study. The immortalized cell line of human urothelial cells (UROtsa) developed in 2001 (Rossi et al., 2001) has demonstrated to be a useful model to study the mechanisms of carcinogenicity associated with human exposure to inorganic arsenicals (Eblin et al., 2008; Escudero-Lourdes et al., 2010; Escudero-Lourdes et al., 2012; Jensen et al., 2009). Chronic exposure of UROtsa to $50 \mathrm{nM}$ of monomethylarsonous acid (MMA ${ }^{\text {III) }}$ commits cells to malignant transformation after just weeks of exposure (Bredfeldt et al., 2006; Wnek et al., 2010). In these cells the inflammatory responses mediated by NF-K $\beta$ activation and pro-inflammatory cytokines over-production (mainly IL13, IL-6 and IL-8), seems to play an important role in malignant transformation (Escudero-Lourdes et al., 2010). However, the link between sustained inflammation and MMA"I -induced cellular transformation has not been established.

In order to find this link, our group focused the attention on the phosphatase and tensin homologue protein (PTEN), the second most important tumor suppressor which is very often lost, mutated, or silenced in many human cancers (Chu et al., 2011; Qian et al., 2009; Sun et al., 2011; Vasudevan et al., 2004; Wang et al., 2012; Zhang and $\mathrm{Yu}, 2010)$. In fact, over $50 \%$ of bladder cells from human bladder cancer patients had decreased PTEN expression which correlates with their stage of cancer (Tsuruta et al., 2006).

In support of this line of reasoning, Waalkes and Tokar have previously demonstrated that arsenic decreases PTEN expression in association with prostate, lung and liver cells malignant transformation (Ngalame et al., 2014; Person et al., 2015; Tokar et al., 2014). It is noteworthy that the external addition of IL-6, a strong NF-k $\beta$ activator, to the prostate epithelial cells cultures correlated with a significant decrease in PTEN expression, suggesting a critical role of the pro-inflammatory pathway in PTEN negative regulation (Xu et al., 2012), however the associated mechanisms were not further studied.

NFK $\beta$-mediated PTEN negative transcriptional regulation has been previously described by several researchers (Kim et al., 2004; Vasudevan et al., 2004; Zhang and Yu, 2010). In addition, at least two different putative NF-k $\beta$ binding sequences at PTEN promoter, the sequence GGGAATCTCT located at -1574 to -1565 nts and the sequence GGGTATTCCC located at -1450 to -1441 nts, through which NF-k $\beta$ can bind and repress PTEN gene transcription in mouse embryonic fibroblasts and in human cells are reported (Vasudevan et al., 2004; Xia et al., 2007). Based in these observations, we propose that NFKB-mediated PTEN negative regulation may be the factor linking inflammation with carcinogenesis in $\mathrm{MMA}^{\prime \prime \prime}$-induced UROtsa cells malignant transformation.

In the literature it has been described that for NF- $\beta$ to activate or repress gene transcription, it induces histone 3 (H3) acetylation or deacetylation, respectively (Bhatt and Ghosh, 2014). To do this, NF-KB recruits 
and interacts with chromatin regulators including histone acetyltransferases (p300/CBP), histone deacetylases 1 and 3 (HDAC1 and HDAC3), and epigenetic reader proteins. Through these interactions, NF-KB is able to engage in crosstalk with chromatin remodeling machinery (Brown et al., 2014).

Interestingly, both in vivo and in vitro studies demonstrated that exposure to iAs and MMA ${ }^{\prime \prime \prime}$ is related to histone post-translational modifications in different cells; in exposed people for example, it has been demonstrated that iAs increases global H3 tri-methylation at lysine 9 (H3K9me3) (Chervona and Costa, 2012; Chervona et al., 2012; Chu et al., 2011). In previous in vitro studies, it was also demonstrated that arsenite modifies global histone acetylation in different cells (Ramirez T, 2008; Li J 2002, 2003). Specifically in UROtsa cells, 12 wk exposure to 50 nM MMA'l' lead to different HDAC's increased expression (Ge et al., 2013).

Based on former observations, we hypothesize that one of the mechanisms of MMA'"-induced UROtsa cells malignant transformation may involve NF- $\beta \beta$ activation and binding to PTEN promoter inducing H3 deacetylation and increasing its methylation at lysine 9 and 27. Together these events will lead to PTEN reduced expression, contributing to the cellular malignant transformation. 


\section{Methods}

\subsection{Cells}

UROtsa cells, were generously provided by Drs. Mary Ann and Donald Sens (University of North Dakota, Grand Forks, ND, USA). Cell culture conditions were those previously described by Bredfeldt el al. (2006). Stock cells cultures were grown on $100-\mathrm{cm}^{2}$ tissue culture flasks using high glucose Dulbecco's modified eagle medium (DMEM), 10\% fetal bovine serum (FBS) and $1 \%$ antibiotic solution at $37^{\circ} \mathrm{C}$ in $5 \% \mathrm{CO}_{2}$. Cells were allowed to reach $85-90 \%$ confluence before the experiments were conducted. Normal non-exposed UROtsa cells as well as passage-matched UROtsa cells chronically exposed every other day to $50 \mathrm{nM} \mathrm{MMA}$ "II were used for all the studies. Cells exposed for $4,12,20$, and $24 \mathrm{wk}$ to $\mathrm{MMA}^{\mathrm{III}}$ were plated as corresponded and allowed to settle prior to performing the assays. Therefore, the observations described at the results section represent sustained changes induced by chronic exposure to MMA'I".

\subsection{Chemicals.}

Diiodomethylarsine $\left(\mathrm{CH}_{3} \mathrm{AsI}_{2}\right)$ was prepared by the Synthetic Chemistry Facility Core (Southwest Environmental Health Science Center, Tucson, AZ, USA). Fresh stock solutions of 25 mM MMA ${ }^{\text {III }}$ were made in distilled, deionized and ultrapure water. A $5 \mu \mathrm{M}$ working solution was used to dose the cells every other day to assure constant exposure to $M M A^{\prime \prime \prime}$.

\subsection{Western-blots analysis.}

Cells were rinsed with cold phosphate-buffered saline, removed from plates by scraping in radioimmunoprecipitation Iysis buffer (RIPA buffer) containing $50 \mathrm{mM}$ Tris-HCl (pH 8.6), 1\% NP-40, 0.25\% C24H39NaO4, $150 \mathrm{mM} \mathrm{NaCl}, 1 \mathrm{mM}$ PMSF, $1 \mu \mathrm{g} / \mathrm{ml}$ aprotinin, $1 \mu \mathrm{g} / \mathrm{ml}$ leupeptin, $1 \mathrm{mM} \mathrm{NaF}, 1 \mathrm{mM}$ Na3VO4, $1 \mathrm{mM}$ EDTA, and $10 \mu \mathrm{g} / \mathrm{ml}$ protease inhibitor cocktail. The lysates were sonicated and centrifuged at $14,000 \mathrm{rpm}$ for $5 \mathrm{~min}$ at $4^{\circ} \mathrm{C}$ to eliminate cellular debris. Protein concentrations were determined by the Bradford method using the Protein Assay solution (BIO-RAD). Fifty $\mu \mathrm{g}$ of protein from each sample was loaded onto $12 \%$ sodium dodecyl sulfate (SDS)/polyacrylamide gels. Samples were separated via SDS-polyacrylamide gel electrophoresis (PAGE) with Mini-Protean II (BioRad, Hercules, $\mathrm{CA}$ ), transferred onto nitrocellulose membranes (Millipore, Bedford, MA) and blocked $2 \mathrm{~h}$ at room temperature with $5 \%$ fat-free milk dissolved in TBS-T (20 mM Tris- $\mathrm{HCl}, 137 \mathrm{mM} \mathrm{NaCl}, \mathrm{pH} 7.6$ and $0.1 \%$ Tween 20). Blots were incubated overnight at $4^{\circ} \mathrm{C}$ with primary antibodies for PTEN and $\beta$-tubulin (Santa Cruz Biotechnologies, Santa Cruz, CA) with gentle stirring at $4{ }^{\circ} \mathrm{C}$. Membranes were then incubate with the secondary antibody coupled to peroxidase antirabbit (dilution 1: 5000) for $1 \mathrm{~h}$ at room temperature. The presence of specific bands was determined by chemiluminescence using luminol as a substrate. The corresponding images were analyzed using image J software, freely available at the web. Results are expressed as relative intensity to $\alpha$-actin which expression was used as protein loading control. 


\subsection{NFkB activation assay.}

Nuclear proteins were isolated through the use of a commercial kit (Panomics, Affimetrix) following the provider's directions. The supernatants were collected and stored at $-80^{\circ} \mathrm{C}$ until use. Total nuclear protein concentration was determined with RC DC Protein Assay (BIO-RAD). NFK $\beta$ activation for cells exposed for 12, 24, and 52 wk to $50 \mathrm{nM}$ MMA'"' was assessed through determination of p65 phosphorylation with a specific ELISA kit (Affimetrix).

\subsection{Chromatin Immunoprecipitation}

Chromatin immunoprecipitations (ChIPs) were performed as described previously (Massie and Mills, 2009). Briefly cells were treated with $1 \%$ formaldehyde for $10 \mathrm{~min}$ to cross-link DNA and protein. Cells were then scraped from culture plates in lysis solution containing the protease inhibitors, 1\% SDS, EDTA $10 \mathrm{mM}$, Tris- $\mathrm{HCl} 50 \mathrm{mM} \mathrm{pH} \mathrm{8,} 1$. Resulting DNA-protein complexes were sonicated and subjected to gel electrophoresis to ensure proper sonication. A portion of the product was removed for later analysis and used as input DNA. The remaining portion was precleared using protein A/G sepharose (BioVision,Milpitas, California), and incubated overnight with an antibody directed toward the subunits p50 and p65 NF-k $\beta$ and to an specific histone 3 modification. Antibodies against acetylated histone $\mathrm{H} 3$ and trimethylated total histone 3 were purchased from Upstate/Millipore (Billerica, MA). Antibodies against NF-K $\beta$ p105/p50 or p65, H3K9me3 and H3K27me3 were purchased from Abcam (Cambridge, MA). After incubation, the bounded DNA was immunoprecipitated by centrifugation, washed and treated with $5 \mathrm{M} \mathrm{NaCl}$ to reverse DNA-protein cross-links, after which protein was digested with proteinase K (Fermentas, Glen Burnie, MD). Immunoprecipitated and input DNA samples were purified using Phenol/chloroform/isoamylic alcohol and were quantified using the Quant-IT Picogreen dsDNA detection kit (Invitrogen, Carlsbad, CA).

\subsection{ChIP coupled to real-time PCR}

Equal amounts of non-immuno-precipitated chromatin (input) and immunoprecipitated DNA (100 ng) were added to iTaqTM Universal SYBR ${ }^{\circledR}$ green SuperMix (Bio-Rad, Hercules, CA), promoter-specific primers (Specific primer sequences are presented in Table 1) and analyzed using the ABI 7500 Real-Time Detection System (Applied Biosystems, Foster City, CA). Values were calculated using the delta Ct method normalizing to the respective input for each sample. 
Table 1. Primers for NF-KB ChiP assays at the PTEN promoter.

\begin{tabular}{|c|c|c|c|c|c|}
\hline & $\begin{array}{c}\text { Location at the PTEN } \\
\text { promoter }\end{array}$ & & Sequence & Amplicon size & $\operatorname{Tm}\left({ }^{\circ} \mathrm{C}\right)$ \\
\hline \multirow[t]{2}{*}{1} & $-1636-1285$ & Fw & 5'-gctggcgacacaatagcagg-3' & 351 & 60 \\
\hline & & $\mathrm{Rv}$ & 5'-ggtggaggactgatgatgaaagc-3' & & \\
\hline \multirow[t]{2}{*}{2} & $-1980-1636$ & Fw & $5^{\prime}$-ttgctttgtagatccttgacgggtg-3' & 344 & 60 \\
\hline & & $\mathrm{Rv}$ & $5^{\prime}$-gttctgtgcttgagggtatctcc-3' & & \\
\hline \multirow[t]{2}{*}{3} & $-2261-1980$ & Fw & $5^{\prime}$-cccgagcaaaggaagaagacgac-3' & 353 & 60 \\
\hline & & $\mathrm{Rv}$ & $5^{\prime}$-cgtcggagtcaagctcggtt-3' & & \\
\hline
\end{tabular}

\subsection{Gene expression analyses}

Total RNA of UROtsa cells exposed to $50 \mathrm{nM} \mathrm{MMA}{ }^{\text {III }}$ for 0-24 wk was isolated using TRIzol reagent (Invitrogen, Carlsbad, CA).The purified RNA was reverse transcribed with SSII retro-transcriptase and Random Primers (Invitrogen, Carlsbad, CA). Absolute iTaqTM Universal SYBR ${ }^{\circledR}$ green SuperMix (Bio-Rad, Hercules, CA) and Universal TaqMan master mix,TaqMan Gene Expression Assay Mix PTEN / GAPDH (Applied Biosystems, Foster City, CA) was used to measure mRNA levels. The cycle threshold times $(\mathrm{Ct})$ were normalized to $\beta$-actin from the same sample. The relative gene expression was conducted through the $\Delta \Delta \mathrm{Ct}$ method. The primers sequences for pro-inflammatory cytokines codifying genes were: IL-6 (F:ccactcacctcttcagaacg; R:catctttggaaggttcaggttg), IL-1ß (F:atgcacctgtacgatcactg; R:acaaaggacatggagaacacc), IL-8 (F:atactccaaacctttccaccc; R:tctgcacccagttttccttg y TNF- $\alpha$ (F:gaaccccgagtgacaagc; R:tcagctccacgccattg) .

\subsection{Statistical analysis}

The results were analyzed by one way variance (ANOVA). Subsequently, the differences between groups were analyzed by the Tukey test, considering a value of $\mathrm{P} \leq 0.05$; this was done using the statistical package GraphPad Prism S1. Data are expressed as the mean \pm standard deviation $(\mu \pm S D)$. $N$ values correspond to three separate samples (cultures) and assays were conducted at least in duplicate for each sample. 


\section{Results}

3.1 Chronically exposed cells show a time-dependent increased NF-kB activation which is consistent with IL-16, IL-6, IL-8 and TNF- $\alpha$ increased expression.

To confirm the MMAIII-induced activation of NF-k $\beta$ in exposed UROtsa cells, the p65 subunit phosphorylation was determined in nuclear proteins from cells exposed for 4, 12, 20 and 24 wk to 50 nM MMA ${ }^{\prime \prime \prime}$. Results showed a significant increase in phosphorylated p65 following just 4 wk which was sustained through the 24 wk constant exposure (Figure 1A). In accordance with NF-k $\beta$ activation results, $M M A^{\prime \prime \prime}$ induced pro-inflammatory cytokine genes over-expression in UROtsa cells when compared with non-exposed cells. IL-1 $\beta$ and IL-6 gene expression was marginally increased by MMA"I during the initial exposure period, while IL-8 was substantially elevated during midexposure (12 and $20 \mathrm{wk}$ ). All these inflammatory cytokines returned to normal levels by the end of the exposure. Interestingly, prolonged exposure (24 wk) was needed to double or triple the gene expression of TNF- $\alpha$ (Figure 1B). 


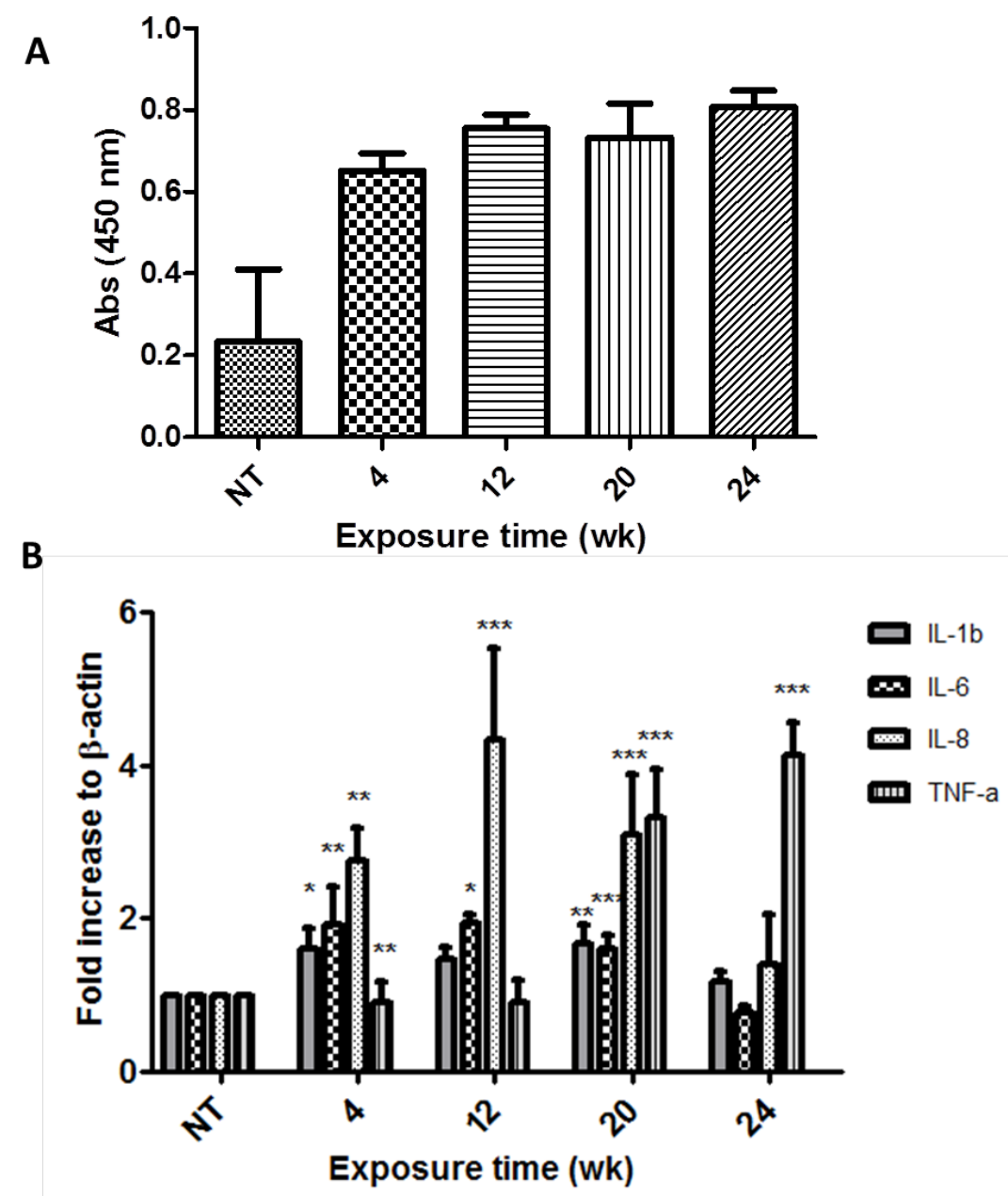

Figure 1 Chronic exposure to MMA"' leads to a sustained increase in NF-k $\beta$ p65 phosphorylation and in pro-inflammatory cytokines gene expression. A. Nuclear proteins from UROtsa cells exposed to $50 \mathrm{nM} \mathrm{MMA}$ "II for 4, 12, 20 and 24 wk were assayed for phosphorylated $p 65 \mathrm{NF}-\mathrm{k} \beta . \mathrm{n}=3$; Asterisks denote significant difference considering ${ }^{+++} \mathrm{P}<0.0001 \mathrm{p}-50$ vs no treated control (NT). B. Gene expression analysis for the pro-inflammatory cytokines IL-6, IL-1 $\beta$, IL-8 and TNF- $\alpha$ was performed by realtime PCR using specific primers. NT cells and treated for 4, 12, 20 and 24 wk. Statistical analysis was performed with $n=3$; Asterisks denote significant differences $* p<0.05,{ }^{* *} p<0.01 * * * p<0.0001$ vs NT. 


\subsection{PTEN protein and mRNA expression is decreased after 20 wk exposure to MMA"I.}

Next, we determined the PTEN gene and protein expression levels in MMA"I long-term exposed cells and its correlation with the previously observed increased NF-K $\beta$ activation. To do it, total RNA and proteins were isolated from exposed cells and processed to assay gene expression and WB-based PTEN immune-detection. Although results showed that PTEN gene expression increased after $12 \mathrm{wk}$ exposure, a significant decrease was observed after $20 \mathrm{wk}$ exposure that continues through $24 \mathrm{wk}$ in both gene (Figure $3 \mathrm{~A}$ ) and protein expression (Figure 3B) after exposure to MMA'".



Figure 3. In vitro long term exposure of UROTsa cells to $50 \mathrm{nM}$ MMA ${ }^{\prime \prime \prime}$ leads to changes in PTEN gene and protein expression. A) Gene expression analysis was conducted by real time-PCR using Taqman probes. B) Western-blot representative image and the corresponding densitometry analysis. NT = no treated cells and cells treated for $4,12,20$ and 24 wk. $n=3$. Asterisks denote significant difference considering $* P<0.05$, , $* * P<0.01 * * * P<0.0001$ vs. NT. $n=3$. 
3.3 Increased NF-K $\beta$ binding to PTEN promoter correlates with PTEN down-regulation after 20 and 24 wk exposure to $M M A^{\prime \prime \prime}$.

Since the PTEN protein levels decreased only after 20 wk exposure to MMA'I', the ChIP assay to evaluate NF-K $\beta$ p50 subunit negative regulation of PTEN expression was performed only with UROtsa cells exposed for 20 and 24 wk to $50 \mathrm{nM} \mathrm{MMA}{ }^{\prime \prime \prime}$. PTEN promoter was amplified in the input and immunoprecipitated chromatin samples only with the use of the primer set No. 1 targeting the sequence GGGTATTCCC located at -1450-1441 nts on the PTEN promoter that was previously reported. Results showed a significant increase in NF-к $\beta$ p50 binding to the specific PTEN promoter region in chromatin from UROtsa cells exposed for both 20 and 24 wk. Surprisingly, cells from the $20 \mathrm{wk}$ exposure had the greatest increase in NF- $\mathrm{K} \beta$ binding (Figure $4 \mathrm{~A}$ ). Immunoprecipitation assays were also conducted with anti-p65 to determine if NF- $\mathrm{k} \beta$ at PTEN promoter was composed exclusively of $\mathrm{p} 50$ homodimers or p65/p50 heterodimers at the different exposure times. Results showed only limited binding of p65 subunit at the PTEN promoter at 20 and 24 wk exposure to MMA ${ }^{\prime \prime \prime}$ (Figure 4B), suggesting that PTEN decreased expression at that time exposure is due to $\mathrm{p} 50$ homodimers binding to specific sequences at the PTEN promoter.



Figure 4.Chromatin immunoprecipitation (ChIP) assay to determine NF- $\boldsymbol{\beta}$ p-50/p65 binding to PTEN promoter. Chromatin from UROtsa cells treated with $50 \mathrm{nM} \mathrm{MMA}$ "ll for 20 or 24 wk was used for this assay. Antibodies against the p105/p50 or p65 subunits of NF-K $\beta$ were used to precipitate chromatin. Amplification by PCR was conducted with three different sets of primers that amplify PTEN gene promoter. Results were obtained only with primer set No. 1 . The percentages of NF-k $\beta$ binding at PTEN and corresponding differences between treatments were calculated through the percentage of input method. NT: not treated cells; -anti-p50 (A), + anti-p65 (B): sample amplified by PCR without immunoprecipitation with the corresponding antibody; + Anti-p50 and +Anti-p65: samples immunoprecipitated with the corresponding antibody and then PCR-amplified. Statistical analysis were performed with an $n=3$; Asterisks denote significant difference considering ${ }^{* *} \mathrm{P}<0.01$ and $* * * P<0.0001 \mathrm{p}-50$ vs NT. 


\subsection{Exposure to MMA"II increases H3K9 and H3K27 methylation and decreases H3 acetylation at the PTEN promoter.}

These studies were performed using the primer set no. 1 that targeted the NF-kB binding sequence at the 20 and 24 wk exposures. The well-known H3K9me3 and H3k27me3 repression markers as well as acetylated $\mathrm{H} 3$, a marker of gene expression activation, were evaluated in UROtsa cells exposed for 20 and 24 wk at PTEN promoter. Results showed that exposure to MMA III for 20 wk led to an increased percentage of H3K9me3 (Figure 5A) and H3K27me3 (Figure 5B) at PTEN promoter as well a significantly decreased percentage of acetylated H3 at 24 wk (Figure $5 \mathrm{C}$ ). These results nicely correlated with the increased binding of NF-k $\beta / \mathrm{p} 50$ to the consensus sequence at PTEN promoter and with the PTEN decreased gene expression.

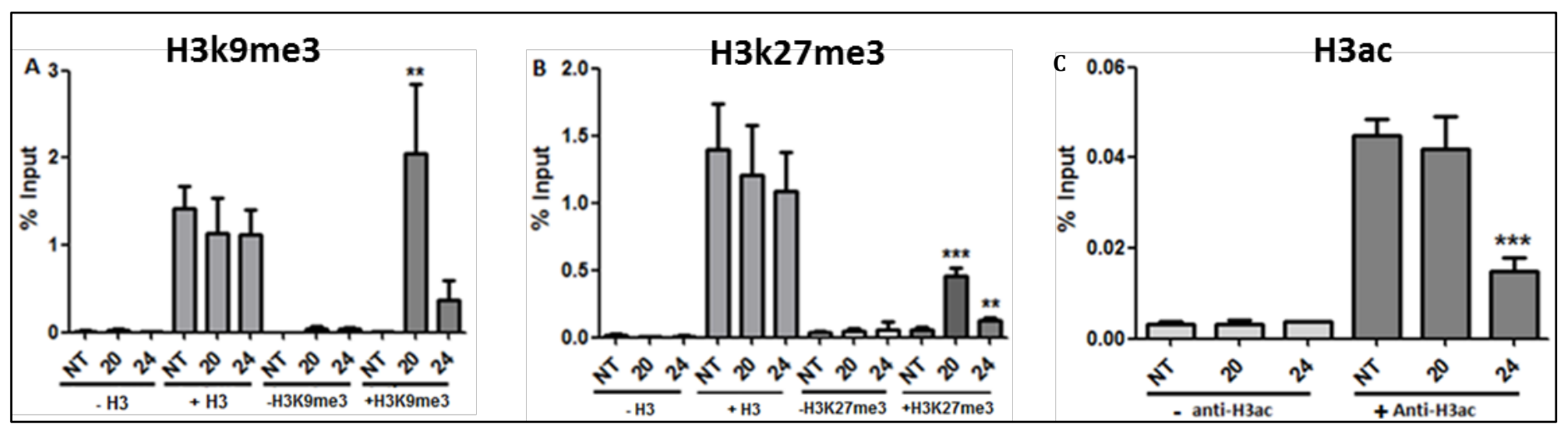

Figure 5. MMA"I increases the H3K3me3, H3K927me3 repression markers but decreases the H3ac activation marker at PTEN promoter in UROtsa cells. Cells exposed to MMA"I for 20 and 24 wk were assayed through ChIP to determine the percentage of these in PTEN promoter using the primer set No. 1. Samples processed with the use of an antibody against total $\mathrm{H} 3$ were included as control for the methylated H3. NT: not-treated cells, $-\mathrm{H} 3$ sample amplified by PCR without precipitation with anti-H3, +H3: sample amplified by PCR after precipitation with anti-H3; -H3K9me3 (A) -H3K27me3 (B) or -anti H3ac: sample amplified by PCR without precipitation with the corresponding antibodies; $+\mathrm{H} 3 \mathrm{~K} 9 \mathrm{me} 3(\mathrm{~A}),+\mathrm{H} 3 \mathrm{~K} 27 \mathrm{me} 3$ (B) and $\operatorname{tanti-H3ac}(\mathrm{C})$ : samples processed after precipitation with the corresponding antibodies. Statistical analysis were performed with $n=3$; the asterisks denote significant difference of $\mathrm{P}=0.4801(+\mathrm{H} 3) ;{ }^{* *} \mathrm{P}<0.01$ and ${ }^{* * *} \mathrm{P}<0.0001(+\mathrm{H} 3 \mathrm{~K} 27 \mathrm{me} 3)$ vs NT. 


\section{Discussion and Conclusions}

Our results demonstrated that constant exposure of UROtsa cells to $50 \mathrm{nM} \mathrm{MMA}^{\text {III }}$ decreased PTEN gene and protein expression but only after 20 and 24 wk exposure. This decrease in PTEN expression correlated with an increased binding of the NF- $\mathrm{K} \beta$ p50 subunit to specific sequences at the PTEN promoter. In addition, the $\mathrm{H} 3$ acetylation status in MMAIII exposed UROtsa cells was found to be decreased compared with non-treated cells, while the gene transcription repression marks, $\mathrm{H} 3 \mathrm{~K} 27 \mathrm{me} 3$ and $\mathrm{H} 3 \mathrm{~K} 9 \mathrm{me} 3$, at the same NF-kB sequence, were significantly higher in exposed cells. Our results also demonstrated that the NF-к $\beta$ bind to PTEN promoter at 20 and 24 wk is composed exclusively by the p50 subunit since chromatin precipitated with anti-p65 antibodies practically did not amplified for the corresponding NF-k $\beta$ binding sequence.

Interestingly, results showed that while PTEN expression significantly increases at $12 \mathrm{wk}$ exposure and then decreases at 20 and 24 wk, NF-k $\beta$ activation, measured as p65 subunit phosphorylation, and pro-inflammatory cytokines IL-1 $\beta$, IL-6 and IL-8 gene expression increased as early as 4 wk exposure to MMA ${ }^{\prime \prime \prime}$ and remained elevated through $20 \mathrm{wk}$ of exposure in the urothelial cells. On the other hand, TNF- $\alpha$ gene expression increases significantly only after $20 \mathrm{wk}$ exposure. These observations suggest that first, PTEN decreased expression in UROtsa cells is not the initial responsible of the increased pro-inflammatory response mediated IL-1 $\beta$, IL-6 and IL-8, but it may contribute to increase the TNF- $\alpha$ gene expression observed at 20 and $24 \mathrm{wk}$ exposure and may play a critical role in UROtsa cells malignant transformation. Secondly, since IL-1 $\beta$, IL-8 and IL-6 expression is mainly induced by NF-K $\beta$, the activity of this transcription factor seems to simultaneously

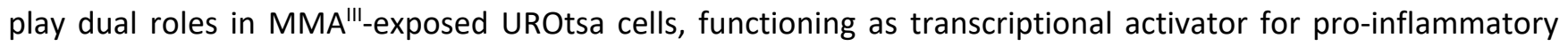
genes and as a negative regulator for PTEN gene expression.

It is important to point out that a variety of tumor cells express decreased PTEN levels even though they have the corresponding PTEN wild type (functional) alleles, suggesting that even a slight change in PTEN protein expression is enough to promote malignant transformation (Vasudevan et al., 2004). This observation has been also reported in bladder cancer (Salmena et al., 2008). In our studies, even though PTEN expression is not completely suppressed in UROtsa cells after 20 wk exposure to MMA"', based in former observations, we propose that its decreased expression may be enough to lead UROtsa cells to malignant transformation.

As it is known, NF-K $\beta$ is part of a family of transcription factors that bind DNA and regulate the expression of a wide variety of genes. Under basal conditions, NF-k $\beta$, which is composed typically by a p50/p65 heterodimer, is sequestered at the cytoplasm by an inhibitor protein belonging to the inhibitor IK $\beta$ family (IKK). The p65 subunit has a transcription transacting domain that favors gene expression, while the p50 subunit is able to bind DNA but lacks the transacting domain. Therefore, only when p65 is present in the dimer, NF-k $\beta$ is able to activate gene transcription, while p50 or p52 homodimers repress gene transcription. After an appropriate stimulus, IK $\beta$ is 
phosphorylated by a cytoplasmic kinase (IKK) releasing NF-K $\beta$ which translocate to the nucleus and inducing the expression of a variety of genes involved in proliferation, differentiation, apoptosis, stress responses, inflammation, and other biological processes.

Our work is the first to demonstrate that MMA"II-induced NF-KB is actually participating in PTEN negative regulation in UROtsa cells which occurs around the time that was previously demonstrated that this cell line becomes committed to malignant transformation. It is also demonstrated by the first time that p50 homodimers but not p65/p50 heterodimers binds to PTEN promoter downregulating its transcription at the indicated exposure times.

In additon, it is known, the chromatin packing status around the genes is an important determinant factor to favor or impede a transcription factor to activate gene expression. As mentioned before, NF- $\mathrm{\beta} \beta$ is itself able to influence chromatin remodeling through diverse mechanisms that depend of its activator or repressor activity for specific genes and under specific conditions. To activate transcription for example, NF-k $\beta$ subunit p65 is acetylated in a lysine residue and induces the recruitment of co-activator complexes such as p300/CBP acetyltransferase and also the SWI/SNF chromatin remodeling complexes, allowing TATA binding protein (TBP) to bind the gene promoter and starting gene transcription process (Bhatt and Ghosh, 2014). To repress gene expression, p50 or p52 homodimers (no p65 subunit present) are directly or indirectly attached to DNA and recruits HDACs and other co-repressor proteins like SWI-independent 3A (mSin3A), the nuclear receptor co-repressor ( $\mathrm{N}-\mathrm{CoR})$ and/or silencing mediator of retinoic acid and thyroid hormone receptor (SMRT)(Calao et al., 2008).

In our studies, we determined the acetylation and methylation status of H3 in the same NF-k $\beta$ promoter binding site. Results showed that $\mathrm{H} 3$ acetylation decreased around NF-k $\beta$ binding site at PTEN promoter, while the gene silencing marks, H3K9me3 y H9K27me3 increased at the same time points in UROtsa cells. These results were also consistent with increased NF-K $\beta$ binding to PTEN promoter and with PTEN decreased expression at 20 and 24 wk exposure, suggesting that in this model, MMA ${ }^{\prime \prime \prime}$-induced NF- $k \beta$ regulates PTEN expression through binding to its promoter as a p50 homodimer, recruiting HDACs and probably histone methyl transferases. Deacetylation of H3 around the PTEN promoter, increases affinity between DNA and histones, and the induction of methylation at lysine 9 and 27 in the same $\mathrm{H3}$, decreasing the accessibility of the gene translation machinery.

Both in vivo and in vitro studies have demonstrated that $\mathrm{MMA}^{\text {III }}$ induces global histone acetylation modifications (Chervona and Costa, 2012; Chu et al., 2011). In fact, through the use of the urothelial cells model, UROtsa, it was recently demonstrated that exposure to $50 \mathrm{nM} \mathrm{MMA}$ III for up to 12 wk leads to a significant increased activity and expression of HDAC's 1,3,4,5,7 and 9 in a time dependent fashion. The same group demonstrated that

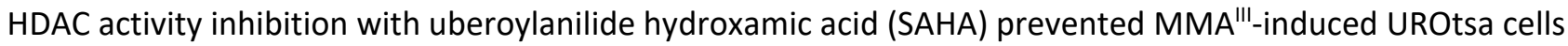
malignant transformation demonstrating the relevance of histone acetylation status in this process (Ge et al., 2013). 
Therefore, besides activating NF-к $\beta$ MMA'I" may also induce global chromatin remodeling, modifying transcription factors accessibility to their DNA specific binding sites and therefore altering gene expression.

Taken together, the results presented here suggest that during long-term exposure to MMA ${ }^{\prime \prime \prime}$, PTEN gene expression is down-regulated in UROtsa cells through the binding of NF-K $\beta$ p50 homodimers to the PTEN promoter, which in turn induce $\mathrm{H} 3$ deacetylation and therefore decreasing PTEN transcription. Results also suggest

that the observed increased tri-methylation at lysine 9 and lysine $27 \mathrm{in} \mathrm{H3}$, in the same NF-к $\beta$ binding site at the PTEN promoter, could be due to the methyltransferases recruitment, an thus disfavoring PTEN gene expression. These mechanisms may be involved in iAs-induced bladder cancer in exposed populations.

\section{Acknowledgements.}

The authors would like to thank Drs. Donald and Mary Ann Sens and Dr. Scott Garret for the kindly donation of UROtsa cells. These studies were partially supported by the NIEHS Superfund Basic Research Program (ES 04940) and Dean Carter Binational Center for Environmental Health Sciences. 


\section{References}

Bhatt, D., Ghosh, S., 2014. Regulation of the NF-kappaB-Mediated Transcription of Inflammatory Genes. Frontiers in immunology 5, 71.

Bredfeldt, T.G., Jagadish, B., Eblin, K.E., Mash, E.A., Gandolfi, A.J., 2006. Monomethylarsonous acid induces transformation of human bladder cells. Toxicol Appl Pharmacol 216, 69-79.

Brown, J.D., Lin, C.Y., Duan, Q., Griffin, G., Federation, A.J., Paranal, R.M., Bair, S., Newton, G., Lichtman, A.H., Kung, A.L., Yang, T., Wang, H., Luscinskas, F.W., Croce, K.J., Bradner, J.E., Plutzky, J., 2014. NFkappaB directs dynamic super enhancer formation in inflammation and atherogenesis. Molecular cell 56, 219-231.

Calao, M., Burny, A., Quivy, V., Dekoninck, A., Van Lint, C., 2008. A pervasive role of histone acetyltransferases and deacetylases in an NF-kappaB-signaling code. Trends in biochemical sciences 33, 339-349.

Chervona, Y., Costa, M., 2012. The control of histone methylation and gene expression by oxidative stress, hypoxia, and metals. Free Radic Biol Med 53, 1041-1047.

Chervona, Y., Hall, M.N., Arita, A., Wu, F., Sun, H., Tseng, H.C., Ali, E., Uddin, M.N., Liu, X., Zoroddu, M.A., Gamble, M.V., Costa, M., 2012. Associations between arsenic exposure and global posttranslational histone modifications among adults in Bangladesh. Cancer epidemiology, biomarkers \& prevention : a publication of the American Association for Cancer Research, cosponsored by the American Society of Preventive Oncology 21, 2252-2260.

Chiou, H.Y., Chiou, S.T., Hsu, Y.H., Chou, Y.L., Tseng, C.H., Wei, M.L., Chen, C.J., 2001. Incidence of transitional cell carcinoma and arsenic in drinking water: a follow-up study of 8,102 residents in an arseniasis-endemic area in northeastern Taiwan. American journal of epidemiology 153, 411-418.

Chu, F., Ren, X., Chasse, A., Hickman, T., Zhang, L., Yuh, J., Smith, M.T., Burlingame, A.L., 2011. Quantitative mass spectrometry reveals the epigenome as a target of arsenic. Chemico-biological interactions 192, 113-117.

Eblin, K.E., Bredfeldt, T.G., Gandolfi, A.J., 2008. Immortalized human urothelial cells as a model of arsenic-induced bladder cancer. Toxicology 248, 67-76.

Escudero-Lourdes, C., Medeiros, M.K., Cardenas-Gonzalez, M.C., Wnek, S.M., Gandolfi, J.A., 2010. Low level exposure to monomethyl arsonous acid-induced the over-production of inflammation-related cytokines and the activation of cell signals associated with tumor progression in a urothelial cell model. Toxicol Appl Pharmacol 244, 162-173.

Escudero-Lourdes, C., Wu, T., Camarillo, J.M., Gandolfi, A.J., 2012. Interleukin-8 (IL-8) over-production and autocrine cell activation are key factors in monomethylarsonous acid [MMA(III)]-induced malignant transformation of urothelial cells. Toxicol Appl Pharmacol 258, 10-18.

Ge, Y., Gong, Z., Olson, J.R., Xu, P., Buck, M.J., Ren, X., 2013. Inhibition of monomethylarsonous acid (MMA(III))-induced cell malignant transformation through restoring dysregulated histone acetylation. Toxicology 312, 30-35.

Jensen, T.J., Wozniak, R.J., Eblin, K.E., Wnek, S.M., Gandolfi, A.J., Futscher, B.W., 2009. Epigenetic mediated transcriptional activation of WNT5A participates in arsenical-associated malignant transformation. Toxicol Appl Pharmacol 235, 39-46.

Kim, S., Domon-Dell, C., Kang, J., Chung, D.H., Freund, J.N., Evers, B.M., 2004. Down-regulation of the tumor suppressor PTEN by the tumor necrosis factor-alpha/nuclear factor-kappaB (NF-kappaB)-inducing kinase/NF-kappaB pathway is linked to a default IkappaB-alpha autoregulatory loop. J Biol Chem 279, 4285-4291.

Ngalame, N.N., Tokar, E.J., Person, R.J., Xu, Y., Waalkes, M.P., 2014. Aberrant microRNA expression likely controls RAS oncogene activation during malignant transformation of human prostate epithelial and stem cells by arsenic. Toxicol Sci 138, 268-277. 
Person, R.J., Ngalame, N.N., Makia, N.L., Bell, M.W., Waalkes, M.P., Tokar, E.J., 2015. Chronic inorganic arsenic exposure in vitro induces a cancer cell phenotype in human peripheral lung epithelial cells. Toxicol Appl Pharmacol 286, 36-43.

Qian, C.N., Furge, K.A., Knol, J., Huang, D., Chen, J., Dykema, K.J., Kort, E.J., Massie, A., Khoo, S.K., Vanden Beldt, K., Resau, J.H., Anema, J., Kahnoski, R.J., Morreau, H., Camparo, P., Comperat, E., Sibony, M., Denoux, Y., Molinie, V., Vieillefond, A., Eng, C., Williams, B.O., Teh, B.T., 2009. Activation of the PI3K/AKT pathway induces urothelial carcinoma of the renal pelvis: identification in human tumors and confirmation in animal models. Cancer research 69, 8256-8264.

Rossi, M.R., Masters, J.R., Park, S., Todd, J.H., Garrett, S.H., Sens, M.A., Somji, S., Nath, J., Sens, D.A., 2001. The immortalized UROtsa cell line as a potential cell culture model of human urothelium. Environ Health Perspect 109, 801-808.

Salmena, L., Carracedo, A., Pandolfi, P.P., 2008. Tenets of PTEN tumor suppression. Cell 133, 403-414.

Sun, C.H., Chang, Y.H., Pan, C.C., 2011. Activation of the PI3K/Akt/mTOR pathway correlates with tumour progression and reduced survival in patients with urothelial carcinoma of the urinary bladder. Histopathology 58, 1054-1063.

Tokar, E.J., Kojima, C., Waalkes, M.P., 2014. Methylarsonous acid causes oxidative DNA damage in cells independent of the ability to biomethylate inorganic arsenic. Arch Toxicol 88, 249-261.

Tsuruta, H., Kishimoto, H., Sasaki, T., Horie, Y., Natsui, M., Shibata, Y., Hamada, K., Yajima, N., Kawahara, K., Sasaki, M., Tsuchiya, N., Enomoto, K., Mak, T.W., Nakano, T., Habuchi, T., Suzuki, A., 2006. Hyperplasia and carcinomas in Pten-deficient mice and reduced PTEN protein in human bladder cancer patients. Cancer research 66, 8389-8396.

Vasudevan, K.M., Gurumurthy, S., Rangnekar, V.M., 2004. Suppression of PTEN expression by NF-kappa B prevents apoptosis. Molecular and cellular biology 24, 1007-1021.

Wang, J., Kobayashi, T., Floc'h, N., Kinkade, C.W., Aytes, A., Dankort, D., Lefebvre, C., Mitrofanova, A., Cardiff, R.D., McMahon, M., Califano, A., Shen, M.M., Abate-Shen, C., 2012. B-Raf activation cooperates with PTEN loss to drive c-Myc expression in advanced prostate cancer. Cancer research 72, 4765-4776.

Wnek, S.M., Jensen, T.J., Severson, P.L., Futscher, B.W., Gandolfi, A.J., 2010. Monomethylarsonous acid produces irreversible events resulting in malignant transformation of a human bladder cell line following 12 weeks of low-level exposure. Toxicol Sci 116, 44-57.

Xia, D., Srinivas, H., Ahn, Y.H., Sethi, G., Sheng, X., Yung, W.K., Xia, Q., Chiao, P.J., Kim, H., Brown, P.H., Wistuba, II, Aggarwal, B.B., Kurie, J.M., 2007. Mitogen-activated protein kinase kinase-4 promotes cell survival by decreasing PTEN expression through an NF kappa B-dependent pathway. J Biol Chem 282, 3507-3519.

Xu, Y., Tokar, E.J., Sun, Y., Waalkes, M.P., 2012. Arsenic-transformed malignant prostate epithelia can convert noncontiguous normal stem cells into an oncogenic phenotype. Environ Health Perspect 120, 865-871.

Zhang, S., Yu, D., 2010. PI(3)king apart PTEN's role in cancer. Clinical cancer research : an official journal of the American Association for Cancer Research 16, 4325-4330. 